\title{
Development of the Energy Potential of the National Economy in the Context of Geopolitical Challenges
}

\author{
Liliana Horal \\ Vice-rector on Scientific and \\ Pedagogical work \\ Ivano-Frankivsk National Technical \\ University of oil and gas \\ Ivano-Frankivsk, Ukraine \\ ORCID 0000-0001-6066-5619
}

\author{
Nadiia Pysar* \\ Department of Theoretical and Applied \\ Economics \\ Vasyl Stefanyk Precarpathian National \\ University \\ Ivano-Frankivsk, Ukraine \\ ORCID 0000-0003-2656-7323 \\ Galyna Bodnar \\ Department of Management and \\ Administration \\ Ivano-Frankivsk National Technical \\ University of oil and gas \\ Ivano-Frankivsk, Ukraine \\ g.bodnar@avangardco.ua
}

\author{
Viktor Oliinyk \\ Economic Cybernetics Department \\ Sumy State University \\ Sumy, Ukraine \\ ORCID 0000-0001-6251-38461
}

\begin{abstract}
The article concentrates on the study of ways to address the issues of development and utilization of the energy potential of the national economy in the context of geopolitical challenges for Ukraine. It presents a theoretical view of the scientific category "energy potential" of the national economy, systematizes the goals, principles and factors of the economic assessment of the natural resource energy potential, analyzes its dynamics, structure and breakdown by Ukrainian regions, studies factors influencing the efficiency of the resource potential of the national economy, as well as proposes directions to increase the level of Ukraine's energy security.
\end{abstract}

Keywords-fuel and energy resources, liberalization, energy security, potential, innovation, globalization, energy market, decarbonization, environmentalism

\section{INTRODUCTION}

In the context of economic liberalization, the successful solution of major problems of socio-economic development is possible due to the implementation of progressive structural changes in the national economy, resulting in the increase in production. This raises attention to raw materials industries, in particular to the energy sector, which has always served as a potent catalyst for the economic growth of the country's socio-economic systems. However, the political conflicts of recent years have accelerated and intensified destructive processes in Ukraine's economy, jeopardized the energy security of the national economy and actually destroyed the existing model and structure of the raw material oriented economy due to the loss of control over gas deposits of the Black Sea shelf and major industrial and energy centers of the country (Fig.4), Donetsk and Lugansk regions, which provided $27 \%$ of the total volume of industrial products sold. The greatest impact on the fall in Ukraine's real GDP was exerted by the loss of the potential of the mining industry and quarrying, which led to a decrease in the growth rate of industrial production by $20 \%$. The generally outlined problematic aspects of the national economy, namely, in the energy sector of Ukraine's economy, updated research on the development of its resource potential and the socio-economic efficiency of its utilization. Analysis of the energy market of Ukraine in the process of integration into the Common European Energy Space substantiates the need to modernize the fuel and energy complex of the national economy.

\section{Critical Literature REVIEW}

Scientific efforts have significantly expanded and enriched research on the nature and impact of the resource potential of the national economy on socio-economic development. In paper [1], the authors propose assessing natural resources at their "fair" value and formed a model for assessing the impact of the intensity of consumption of natural resources on economic growth. However, it would be worth highlighting the most significant resource factor of influence on the growth of the national economy of Ukraine in the context of geopolitical challenges. For instance, the authors of paper [2] examine the problems of growing demand for water resources, the spatial disproportion of water availability and the predictive assessment of its demand, but they do not offer conceptual basis for the development of the water-resource potential of the national economy, which would contribute to the growth of the aggregate productivity of all fresh water sources. An example of such a conceptual approach to the development of the national economy could be the concept of spatial polarization. Methodological approaches to the economic assessment of the natural resources potential were proposed in paper [3], however, the authors did not determine the value of the energy potential of the territory for specifying the development of a given activity in the territory. The authors of paper [4] took into account the influence of global technological growth on the formation of the sustainable potential of national economic development. According to the authors of paper [4], it is possible to ensure 
the systemic efficiency of the national economy in the long term through the development of innovative and technological potential, optimization of utilization of the energy-efficient potential, and intensification of the creative and educational potential, which is especially important for the development of the energy industry in Ukraine. In fact, the development of innovative and intellectual and technical and technological space is relevant in the conditions of transformational changes in the national economy. However, the authors of paper [4] did not study the influence of intellectual and innovative components on the development of the country's resource potential, energy efficiency of technological growth and on the development of the transition from traditional raw material models to models of high-tech intellectual production, which could be represented as an indicator of economic efficiency, as this, for example, is partially presented in paper [5]. At the same time, no attention is paid to economic calculations. On the contrary, papers [6] and [7] clearly define the growth effect of the GDP potential after reforming the national economy through technological progress and industrial transformation. The authors also addressed the issue of decarbonization, which is extremely relevant for the national economy of Ukraine. Thus, the author of paper [8] analyzed the current energy policy and prioritized emission reductions due to higher emissions prices with market reforms and innovation policies with a targeted portfolio for specific innovative needs. In addition, the study [9] found that the consumption of renewable energy adversely affects economic growth, and the principal sources of economic growth of the country such as energy consumption and development of labor potential have an economic effect in the short term. This means that the findings are in line with the neoclassical theory, according to which the economy can maintain stability in the long term due to domestic production, which ensures full deployment of resources due to price and wage flexibility. We also focus on domestic production and ensuring the energy security of the national economy of Ukraine in the context of geopolitical challenges, through the prism of developing the country's own energy potential. Thus, paper [10] substantiates the principles of forming an energy polarized space on the principle of developing the existing energy potential in the country in terms of assessing the density of fuel and energy resources. This allows making strategic decisions and predictive estimates of the development of the energy market. In this article we conduct the retrospective and predictive analyses of the energy potential of the national economy and research on the problems of its effectiveness in the context of market economy. The topic of our study was determined by aggravated issues on improving socioeconomic efficiency and ensuring sustainable utilization of the resource potential of the national economy in market conditions, on the one hand, and the need for the development of scientific recommendations, on the other hand.

\section{Purpose, Methodology AND ScIENTIFIC Novelty}

The purpose of this study is to identify promising trends of effective and sustainable utilization of the energy potential of the national economy in the context of geopolitical challenges. This purpose was set up in connection with the situation and problems that resulted from resource losses of energy potential in eastern Ukraine and the need to develop trends of sustainable utilization of the resource potential in the context of liberalization of the Ukrainian energy market, taking into account environmental services' concerns about environmental pollution, which leads to the development of decarbonization trends in the socio-economic system.

The methodological basis of this study is formed by a set of general scientific and special techniques and methods, namely, the concepts of transition from the growth theory to the theory of sustainable development and the efficiency theory for a theoretical generalization of the research results; scientific abstraction for theoretical generalization of findings of research into the issues of formation of polarized space; comparative analysis for finding out the components of the region's energy potential; quantitative and correlation analysis for determining the influence of factors on the formation of Ukraine's energy potential. The statistical and information bases of the study are formed by scientific works of domestic and foreign scientists and practitioners, legislative and regulatory acts, the State Statistics Service of Ukraine, the State Service of Geology and Mineral Resources of Ukraine.

The scientific novelty of the study is to identify causal relationships between the level of utilization of the natural resources potential, its qualitative indicators and macroeconomic parameters of the national development and the development of conceptual framework for sustainable utilization of the energy potential in the national economy in the context of European integration and liberalization of the Ukrainian energy market, taking into account the need for decarbonization of socio-economic system. The scientific position of our research is aimed at shaping a sociallyoriented market economy in Ukraine.

The results of the study that contains scientific novelty in terms of analyzing the uneven distribution of the energy potential in the national economic system, the efficiency levels of production, processing and sale of fuel and energy resources are useful for creating an economy structure with predominant finished-product output, because the production trend of the national economy is characterized by incomplete production cycle in the utilization of the energy resource potential, which does not contribute to an effective and dynamic combination of high levels of economic and social development. The practical significance of the findings consists in the use of organizational and methodological approaches and scientific recommendations in the areas of utilization of the energy potential of the national economy in making strategic decisions for its development, which are useful for predictive assessments of the demand for energy potential in terms of ensuring its sustainable utilization in the context of market relations.

\section{EMPIRICAL RESULTS}

We proceeded from the fact that any growth of the national economy depends upon the availability of the natural resources potential, its spacial location and utilization. Therefore, we have proposed a methodological framework for studying the processes of the energy potential development, which are based on the principle of systemicity, which means consideration of the values of all managerial aspects in the context of integration of the 
Ukrainian energy market into the Common European Energy Space for the most efficient development of the energy potential of the national economy. The author's concept of utilization of the energy potential is shown in Figure 1, where the energy potential is the totality of explored traditional and non-traditional energy sources, a complex of engineering structures and technologies, transport and energy networks, production capacities of the energy market, as well as an intellectual resource.

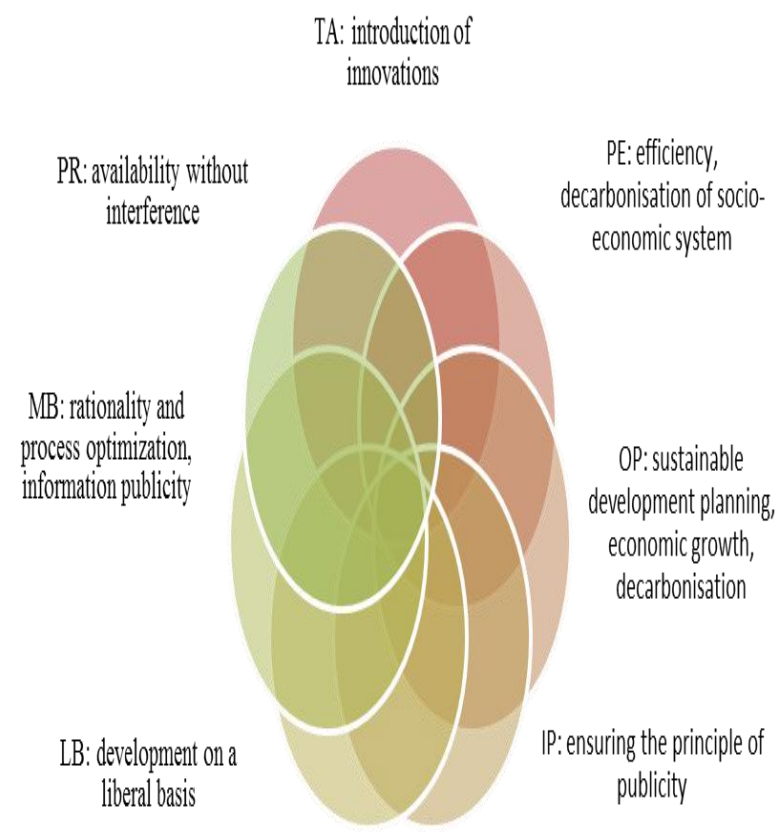

Fig. 1. Model of the concept of utilization of the energy potential in the context of European integration

In accordance with the conceptual vision of utilization of the energy potential of the national economy and the development of integration processes in the Common European Energy Space, this model signals that today the country should place a priority on the development of the legal framework (LB) on liberal principles; the managerial foundations (MB) should be based on the principles of rationality and optimization of processes, as well as information publicity; the development of the Common European Energy Space should minimize regional features (PR) of accessibility barriers to the development of energy potential; theoretical aspects of the development of energy potential should be based on the directions of introducing innovations in production processes (TA), including significantly increasing the efficiency of practical use (PE) of energy potential and will contribute to the decarbonization of the socio-economic system; the theoretical aspects of development of the energy potential should be based on the trends of introducing innovations in production processes, which will significantly increase the efficiency of actual utilization (OP) of the energy potential and will contribute to the decarbonization of socioeconomic system; the optimal management should be based on sustainable development planning, ensuring economic growth and decarbonization; the global best practices (IP) and ensuring the principle of publicity in the development of processes for the formation of the Common European Energy Space based on the fair principles of utilizing the energy potential of the national economy can be chained at micro, macro and meso levels.

Market-based economy forms a difficult task of comparing the efficiency of fuel and energy resources, for which purpose their rate of delivery should be established, which in turn can be calculated provided the resources that were used are accurately estimated. In other words, the energy potential utilization efficiency indicator should include a cost estimate of all fuel and energy resources involved in production and consumption, since in the market conditions the cost of fuel and energy resources used during the year can be estimated on the basis of market prices, which are formed under the influence of supply and demand. Price should express the condition of natural scarcity and consumer value. A characteristic indicator of the efficiency of utilization of fuel and energy resources is the level of resource intensity over time, which reflects the effects of various factors, for example, technology improvements, introduction of sustainable (low-waste) production, etc.

In this study, we have analyzed each item of the energy potential, namely: gas reserves, MMCM; gas condensate reserves, TT; oil reserves, TT; brown coal reserves, TT; coal reserves, TT; peat reserves, TT with the conversion of absolute values in tons of standard fuel (Figures 2, 3).

The Figure 4 presents an assessment of energy resource potential by region of Ukraine. The Figure 4 clearly shows that the balance reserves of fuel and energy resources are most concentrated in the Donetsk and Luhansk regions, which Ukraine a lost, as well as in the Dnipropetrovsk region.

Using the correlation and regression analysis, an estimated figure of the level of energy resource potential for the national economy of Ukraine for the next years has been determined given constant rates of production of fuel and energy resources. The given lookback and predictive analysis of fuel and energy resources shows that the expected volume of the energy resource potential can be reduced to 38.8 billion tons of standard fuel by 2023 given the last year's tendency of fuel and energy resources extraction rates in Ukraine.

Given the exhaustive and non-renewable nature of the energy resource potential (in our example), the national economy requires an integrated fuel and energy resource management system that will be able to combine all the institutions designed to plan, regulate and monitor the natural resources potential in Ukraine on the legislative, executive, institutional, economic (production and production and service), social and infrastructural levels requiring the involvement of innovative regulatory tools and European development principles. 


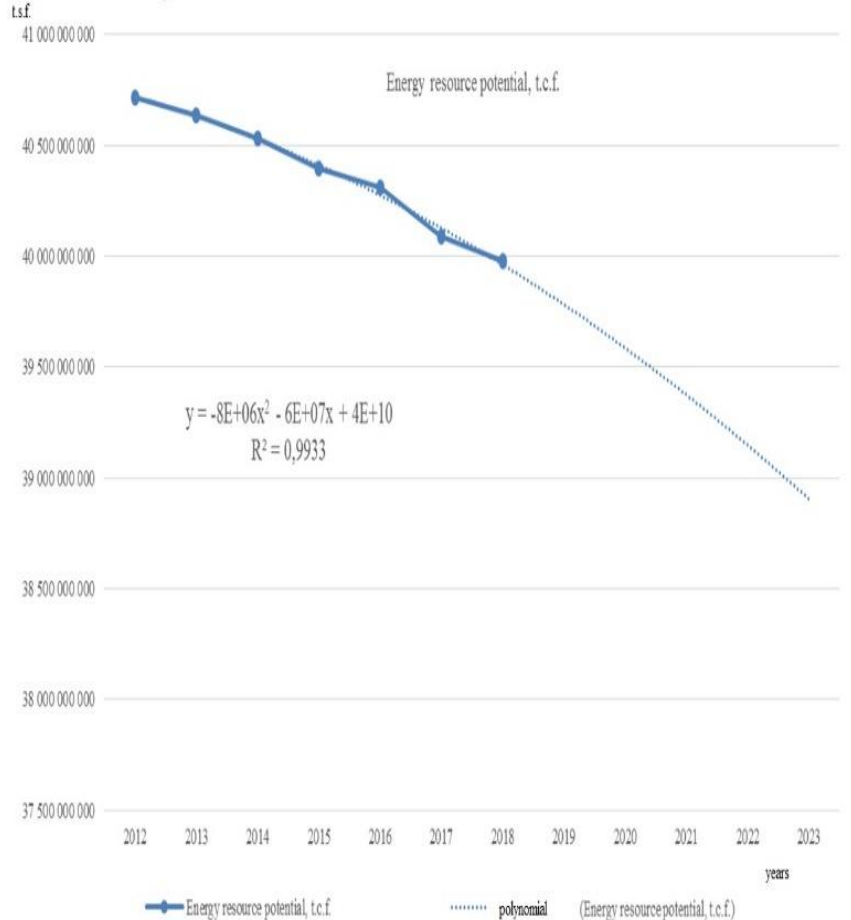

Fig. 2. Retrospective and predictive data of energy potential reserves of the national economy in general



Fig. 3. Retrospective and predictive data of energy potential structure of energy resources reserves of the national economy

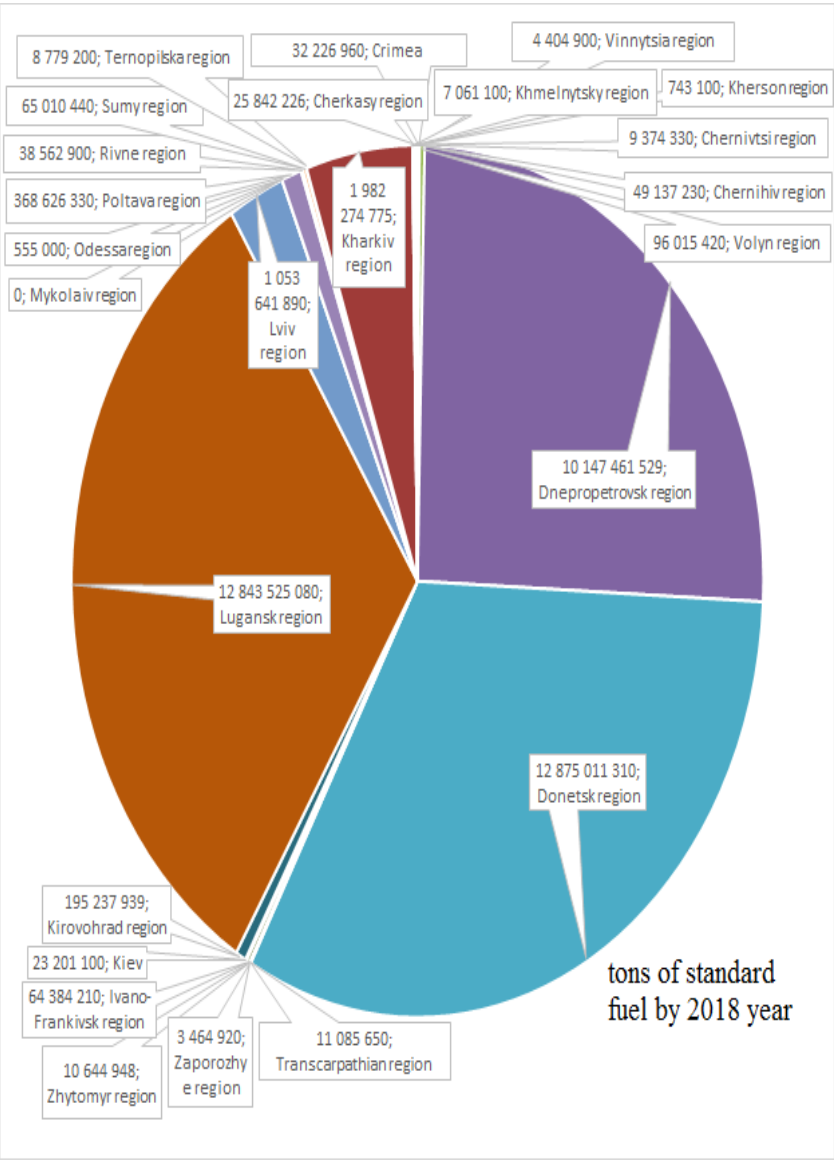

Fig. 4. Energy resource potential of Ukraine in 2018 year, t.s.f.

It is possible to increase the level of sustainable utilization of fuel and energy resources in a market environment through tariff and non-tariff public administration tools. Thus, by increasing mining rents or establishing fixed high coal prices, the state will encourage the expansion of utilization of non-traditional and renewable energy sources (water power, thermal water, sun, wind, etc.), increase the requirements for the use of advanced technologies, as well as update the need for sustainable and economical use while retaining ownership of the subsoil. For the state, which finds itself in a protracted economic crisis, it is essential to attract foreign capital in the form of direct, portfolio investments and other assets in all spheres of the country's economic life. This will help ensure the reproduction of the natural resources potential on a new research and technology basis and will translate into the country's competitive positions in the world market.

\section{CONCLUSION}

As a result of the study, it was found that the national economy of Ukraine has the necessary energy raw material base for its effective development and energy independence, as well as the potential to develop trends for integrating the Ukrainian energy market into the Common European Energy Space, to develop world economic relations as a producer and supplier of finished products. It is stated that the development of the energy raw material base is impossible without the active attraction of foreign direct investment, the use of advanced technologies and achievements of modern geological science for identifying energy potential. 
The author's concept of utilization of the energy potential on the principles of systemicity is presented, which means consideration of all aspects of utilizing this potential and scientific assessment of the existing systems of state regulation of the energy market in the context of its liberalization and decarbonization.

It is noted that the state regulation of Ukraine's fuel and energy complex so far uses extensive methods of utilization of the energy potential, which contradicts the principles of sustainable development of the national economy.

The scientific idea of the structural and innovative capacities of the transition to intensively sustainable utilization of the energy potential has been developed, within which the production function of state management in the context of geopolitical challenges has been identified as a priority. This means that we adhere to the position on bringing the processes of utilizing fuel and energy resources to the end of the full production cycle in terms of the national economy, which can provide positive trend of macroeconomic indicators: increased share of finished products in the export profile, increased state budget revenues, energy independence, general positive level of energy and economic security.

It has been proven that the scientific provisions on the need to combine economic, social and sustainable development on the basis of achieving the highest possible level of completeness of production cycles are essential for the development of environmentalism trends, which sets a new scientific challenge for researchers: the establishment of an optimal combination of relationships between constant, economic and social sectors of development of the national economy.

\section{REFERENCES}

[1] O. Popova, K. Belousova, and O. Tomashevska, O. Kulakov, "Role of natural resource potential in economic growth of ukrainian economy: institutional dimension”, Economics of industry, № 1-2 (61-62), pp. 297-302, 2013

[2] A. Golikov, and N. Kazakova, "Water resource potential of the world economy: problems of use and protection", Bulletin of the VN Karazin Kharkiv National University. Series: International Relations. Economy. Country Studies. Tourism, Vol. (6), pp. 25-32, 2017.

[3] V. Balashenko, M. Ignatyeva, and V. Loginov, "Natural resource potential of northern regions: methodological characteristics of comprehensive assessment", R-Economy, Vol. 1(4), pp. 638-647, 2015

[4] I. Movchan, and O. Ishchenko-Padukova, "The potential of national economic development in the context of global technological growth", Problems of economy. State and municipal government. Scientific notes, Vol. 4, pp.107-111, 2018.

[5] D. Rodionov, A. Liudmila, and I. Rudskaya, "Innovation potential of regions as a factor of national economy competitiveness", Actual problems of economy. Development of productive forces and regional economy, Vol. 8 (158), pp. 215-223, 2014.

[6] Y. Fuhua, "The Potential Economic Growth of China with Restraint of Low Carbon Economy", Economic Research Journal, Vol. (8), 2010

[7] Economic growth and development with low-carbon energy. [Online].Available:https://assets.publishing.service.gov.uk/media/5a2 532fded915d458b922ee6/Working-paper-267-Fankhauser-Jotzo.pdf Accessed on: May 19, 2019.

[8] C. Fischer, "Green Competitiveness". [Online]. Available: https://ec.europa.eu/economy_finance/events/2011/2011-11-21annual-research-conference en/pdf/session032 fischer_en.pdf Accessed on: May 19, 2019.

[9] Jaka Sriyana, "Dynamic Effects of Energy Consumption on Economic Growth in an Emerging Economy", International Journal of Energy Economics and Policy, Vol. 9(4), pp. 283-290, 2019.

[10] V. Dergachova, and N. Pysar, "Prospects for the formation of a polarized energy space: an approach to data analysis" Bulletin of Mariupol State University. Economy series, Mariupol, Vol. 16, pp. 11-20, 2018. 